\title{
Relatedness within clusters of a bird-dispersed pine and the potential for kin interactions
}

\author{
WILLIAM S. F. SCHUSTER \& JEFFRY B. MITTON \\ Department of Biology, University of Utah, Salt Lake City, UT 84112 and Department of Environmental, Population and \\ Organismic Biology, University of Colorado, Boulder, CO 80309, USA
}

\begin{abstract}
Limber pine is a bird-dispersed species that frequently exhibits a multiple-trunk growth form. Previous studies have documented genetically distinct individuals within such groups of trunks, presumably resulting from bird seed caches. We surveyed every trunk of each tree in an isolated population of limber pine at 10 electrophoretic loci to determine how many trees were present and to estimate the relatedness of trees within clusters. Fewer than 20 per cent of the multi-trunk groups were found to contain multiple individuals. Damage to growing leaders (and possibly other unknown mechanisms) has apparently resulted in a multi-trunk growth form in single trees. Tree clusters contained from 2 to 4 individuals, and we estimate that trees within these clusters are related as slightly less than half-sibs, on average $(r=0.19 \pm 0.10)$. The occurrence of kin groups in limber pine indicates the potential for interactions such as kin selection and sib competition. Examination of connections between these trees revealed frequent root and trunk fusion, usually between more genetically similar trees. We discuss the possibility that this trait evolved through kin selection.
\end{abstract}

Keywords: electrophoresis, kin selection, limber pine.

\section{Introduction}

Has kin selection been an important force in shaping the interactions among plants in nature? Kin selection theory states that behaviours which affect the fitness of relatives will be favoured by natural selection if the increment to inclusive fitness is positive:

$$
\Delta w_{x}+\Delta w_{y} r_{y x}>0
$$

where $\Delta w_{x}$ and $\Delta w_{y}$ are the effects of the behaviour on the actor and recipient, and $r_{y x}$ is the relatedness of the recipient to the actor (Hamilton, 1964). In animals, this theory has been used to explain the evolution of altruistic behaviours, such as helpers at nests in communally breeding birds (Brown, 1978), sterile worker and soldier castes in insects (Hamilton, 1963, 1964), and co-operative food capture and egg protection in spiders (Roeloffs \& Reichert, 1988). The theory can also be extended to predict when the interests of kin will be in accord and when they will conflict (e.g. Trivers, 1974). For example, asymmetric relatedness among nestmates can be used to explain why social insect interactions span a range from altruism and cooperation to conflict and aggression (Seger, 1990). In plants, kin selection and inclusive fitness arguments have been used to explain the evolution of triploid endosperm (Charnov, 1979; Westoby \& Rice, 1982; Quellar, 1983), ovule number and pollen clumping (Kress, 1981), seed germination polymorphisms (Westoby, 1981; Ellner, 1986), and aspects of embryology and development (Haig, 1986, 1987). To date, however, there is little direct evidence that it has been important in shaping interactions among adult plants.

For kin selection to operate among adult plants they must be able to affect the fitness of other plants, and to direct their actions towards relatives (Quellar, 1989). Evidence accumulated in recent decades indicates that many plant populations are genetically structured, and limited seed and pollen dispersal are often implicated as reasons for such structuring (Levin \& Kerster, 1974; Schaal, 1975; Linhart et al., 1981; Loveless \& Hamrick, 1984; Epperson, 1990). However, we generally do not know whether kin are clustered close enough to interact, and relatedness has only recently been investigated in natural populations (Meagher \& Thompson, 1986; Ritland, 1990). Such estimates of relatedness are a prerequisite for any investigation of kin interactions in plant populations. In addition, the knowledge of 
relatedness within populations could provide important information regarding dispersal and gene flow, natural selection and long-term fitness in plants.

Bird-dispersed pines are one group of plants which may often occur in family groups, and thus may experience kin interactions. Primarily as a result of seedcaching by birds, seedlings of these species may germinate simultaneously in close proximity, then grow to maturity as a tree cluster of different genotypes (Woodmansee, 1977; Lanner, 1980; Lanner \& Vander Wall, 1980; Tomback, 1982; Linhart \& Tomback, 1985; Furnier et al., 1987). Such bird-pine mutualisms occur in several species of pines, generally associated with birds of the family Corvidae (Tomback \& Linhart, 1990). They occur over much of Europe, Asia and North America, and thus consequences of these interactions may be of wide significance.

Balda (1980) first suggested that seeds from the same parent may be cached together, and based upon simulations, Tomback (1988) estimated that 73-93 per cent of bird-dispersed seed caches would contain two or more sibs or half-sibs. In whitebark pine (Pinus albicaulis), Furnier et al. (1987) demonstrated that trees within clusters were more genetically similar than trees from different clusters. Tomback (1988) and Tomback \& Linhart (1990) have discussed the possibility of kin selection operating in these clusters, but the degree of relatedness within clusters has yet to be documented.

Limber pine (Pinus flexilis) is a bird-dispersed pine of the western United States that frequently grows in multiple-tree clusters (Woodmansee, 1977; Linhart \& Tomback, 1985). In this study we used genetic data and computer models to estimate the relatedness of limber pine trees within clusters. Using starch gel electrophoresis, we surveyed every trunk of each tree in a population to determine how many individuals were present within such clusters. In the process we developed methods to assess the power and limitations of electrophoresis to differentiate genetic individuals. Once we had determined that some clusters contained multiple individuals, we used two different methods to estimate the relatedness of cluster members. We found that in this population, individuals within clusters are related as half-sibs, on average. We also present evidence that non-competitive and potentially altruistic interactions between kin occur, and consider the possibility that these traits may have evolved through kin selection.

\section{Materials and methods}

The study population was an isolated stand of limber pine located on the Pawnee National Grasslands in northeastern Colorado about $90 \mathrm{~km}$ east of the Rocky
Mountains. The site is near the eastern extreme of the range of limber pine and is also near the periphery of the range of the Clark's Nutcracker (Nucifraga columbiana), the primary disperser of limber pine seed (Little, 1971; Lanner \& Vander Wall, 1980; Tomback \& Kramer, 1980; Tomback \& Linhart, 1990). The population consists of 253 trees with a single trunk and 108 multiple-trunk entities containing from two to seven trunks.

Needle tissue was collected from each of the 538 trunks in the population, ground in liquid nitrogen with the buffer of Mitton et al. (1979), and 10 polymorphic loci were scored for each trunk on four different buffer systems. Phosphoglucomutase (PGM-2) was scored on the histidine II buffer of King \& Dancik (1983). Uridine-5-diphosphoglucose isomerase (UDP-1 and UDP-2), 6-phosphogluconate dehydrogenase (6PGD-1 and 6GPD-2), and malate dehydrogenase (MDH) were scored on a tris-citrate buffer system at $\mathrm{pH} 6.7$ (Selander et al., 1971). Phosphoglucose isomerase (PGI), shikimate dehydrogenase (SDH), and peroxidase (PER-2) were scored on the discontinuous triscitrate buffer system of Poulik (1957). Fluorescent esterase (FE-2) was scored on a modified version of the Poulik buffer (J. Hamrick, personal communication). Electrophoresis of gametophyte tissue has demonstrated Mendelian inheritance for all loci except PER-2, which is not expressed in seeds. Several trees were multiply sampled at different times and from different parts of the canopy but no evidence of seasonal variation or somatic mutation was found for any of these loci.

We estimated $B$, our probability of making a type II error (accepting the null hypothesis that trunks with the same multi-locus genotype were part of one tree when they were actually different), for each pair of trunks in each multi-trunk group assuming varying degrees of relatedness. The probability of sampling two trees with an identical $n$-locus genotype is equal to the product of the probabilities of an identical genotype at each locus, assuming loci are unlinked:

$B=\prod_{i=1}^{n} P\left(g_{i}\right)$

where $P\left(g_{i}\right)$ is the probability of genotype $g_{i}$ at locus $i$. The probabilities of identical genotypes at each locus depend on the degree of relatedness, genotype and allele frequencies in the population and expected Mendelian segregation ratios as listed in Table 1 . These error probabilities were then summed over all 245 comparisons of pairs of trunks within multi-trunk groups that did not differ at any of the 10 loci to compute the cumulative error rate. The overall power was estimated as $1-B$ (Sokal \& Rohlf, 1981). 
Table 1 Probability of two trees in a cluster having identical genotypes at a locus, based on relationship

\begin{tabular}{|c|c|c|c|}
\hline \multicolumn{2}{|c|}{ Relationship } & $P\left(g_{i}\right)$ & $P\left(g_{j}\right)$ or $P\left(g_{l}\right)$ \\
\hline \multicolumn{2}{|l|}{ Unrelated } & $f\left(g_{i}\right)$ & \\
\hline \multicolumn{2}{|l|}{ Half-sibs } & $\sum_{j=1}^{k}\left[P\left(g_{j}\right) \times\left(N_{j} / 2\right) \times f(q)\right]$ & {$\left[f\left(g_{j}\right) \times N_{j}\right] / \sum_{j=1}^{k}\left[f\left(g_{j}\right) \times N_{j}\right]$} \\
\hline \multirow{2}{*}{\multicolumn{2}{|c|}{ Full-sibs }} & $\sum_{j=1}^{k} \sum_{l=1}^{m}\left[P\left(\mathrm{~g}_{\mathrm{j}}\right) \times P\left(\mathrm{~g}_{l}\right) \times P\left(M P_{j l}\right)\right]$ & {$\left[f\left(g_{j}\right) \times N_{j}\right] / \sum_{j=1}^{k}\left[f\left(g_{j}\right) \times N_{j}\right]$} \\
\hline & & & $\begin{array}{l}\text { or } \\
{\left[f\left\langle g_{l}\right\rangle \times N_{l}\right] / \sum_{l=1}^{m}\left[f\left\langle g_{l}\right\rangle \times N_{l}\right]}\end{array}$ \\
\hline Selfs & & $\sum_{j=1}\left[P\left(g_{j}\right) \times P\left(M_{j}\right)\right]$ & $f\left(g_{j}\right) \times\left(N_{j}\right)^{2}$ \\
\hline \multicolumn{4}{|l|}{ where: } \\
\hline$P\left(g_{i}\right)$ & \multicolumn{3}{|c|}{ Probability of an identical genotype at locus $i$} \\
\hline$P\left(g_{j}\right)$ & \multicolumn{3}{|c|}{ Relative probability of maternal genotype $j$} \\
\hline$P\left(g_{l}\right)$ & \multicolumn{3}{|c|}{ Relative probability of paternal genotype $l$} \\
\hline$f\left(g_{i}\right)$ & \multicolumn{3}{|c|}{ Frequency of genotype $g_{i}$ in population } \\
\hline$k$ & \multicolumn{3}{|c|}{ Number of possible maternal genotypes at locus $i$} \\
\hline$f(q)$ & \multicolumn{3}{|c|}{$\begin{array}{l}\text { Frequency of allele supplied by paternal parent }[f(q)=(f(a)+f(b)) / 2 \text { for } \\
\qquad a b \text { heterozygotes }]\end{array}$} \\
\hline$f\left(g_{j}\right)$ & \multicolumn{3}{|c|}{ Frequency of genotype $g_{j}$ in population } \\
\hline & \multicolumn{3}{|c|}{ Number of alleles in common between $g_{i}$ and $g_{j}$} \\
\hline & \multicolumn{3}{|c|}{ Number of possible paternal genotypes at locus $i$} \\
\hline$P\left(M P_{j l}\right)$ & \multicolumn{3}{|c|}{$\begin{array}{l}\text { Probability of maternal genotype } g_{j} \text { and paternal genotype } g_{l} \text { producing } \\
\text { offspring with genotype } g_{i}\end{array}$} \\
\hline$f\left(g_{l}\right)$ & \multicolumn{3}{|c|}{ Frequency of genotype $g_{l}$ in population } \\
\hline$N_{l}$ & \multicolumn{3}{|c|}{ Number of alleles in common between $g_{i}$ and $g_{l}$} \\
\hline$P\left(M_{j}\right)$ & \multicolumn{3}{|c|}{ Probability of parental genotype $g_{j}$ producing genotype $g$ upon selfing } \\
\hline
\end{tabular}

We used two methods to estimate the degree of relatedness of individuals within clusters. First, we compared the observed distribution of the number of loci differing between trees within clusters to expected distributions generated by computer for varying degrees of relatedness. These simulations were based on the allelic frequencies in the population, comparing randomly generated pairs of individuals and gametes based on none, one, or two common parents. In each simulation we used 4000 iterations to produce the expected distribution. The observed distribution of genetic differences was then compared to each of the computer-generated distrubutions using a Komolgorov-Smirnov two-sample test (Sokal \& Rohlf, 1981). This test is conservative when applied to discontinuous distributions; no exact test is available for discontinuous distributions with large sample sizes.

We also used the estimator of Quellar \& Goodknight (1989) to estimate average relatedness within clusters.
We calculated relatedness $(r)$ as

$$
\frac{\Sigma_{j} \Sigma_{k} \Sigma_{i} \Sigma_{a}\left(p_{j(-k) m}-p_{m}\right)}{\Sigma_{j} \Sigma_{k} \Sigma_{i} \Sigma_{a}\left(p_{j k m}-p_{m}\right)}
$$

where groups (clusters) were indexed by $j=1, \ldots, n_{j}$, individuals within groups by $k=1, \ldots, n_{k}$, loci by $i=1$, $\ldots, n_{i}$, allelic positions by $a=1,2$, and for any allele designated $m, p_{m}$ is the population frequency of that allele, $p_{j k m}$ is the frequency of that allele in individual $k$ of group $j$, and $p_{j(-k) m}$ is the frequency of that allele in group $j$ excluding individual $k$. As we could not assume such estimators are normally distributed, we used a jackknife procedure over clusters to estimate the standard error or our relatedness estimates.

We visually observed root grafting and trunk fusion between some members of clusters and used a nonparametric test (Mann-Whitney $U$ ) to compare the relatedness estimates between grafted trees to the esti- 
mates between trees that lacked obvious connections. For seedling clusters we were able to excavate to the roots and determine whether grafting had occurred. For adult trees, however, our observations of grafting were limited to above-ground or immediately belowground areas, and thus some trees that were not obviously grafted may actually have had grafts between deeper roots. We also killed one cluster of four seedlings to examine the degree of physiological integration between the wood tissue of fused seedlings. To present the results we have adopted the suggestion of Tomback et al. (1990) to refer to single trees with multiple trunks as multi-trunk trees, and to refer to clusters with more than one genotype as tree clusters.

\section{Results}

Only 19 of the 108 multi-trunk groups ( 17.6 per cent) contained more than one genotype at the 10 loci we examined (Table 2). A total of 132 genetically distinct individuals occurred within these groups, which indicates that 24 trees would have escaped detection if we assumed that each multi-trunk group represented a single tree. Three-trunk and four-trunk groups contained multiple individuals more frequently than other classes, with a maximum of four different individuals in any cluster.

With the high level of genetic variation scored in the Pawnee population, the chance of two individuals in any given cluster with identical 10-locus genotypes was generally quite small, but depended on their degree of relatedness (Table 3 ). The mean probability of such an occurrence ranged from less than 1 per cent for unrelated individuals or half-sibs, to just over 6 per cent for sibs in clusters resulting from selfing. Our estimation of cumulative error indicates that we are unlikely to have missed more than a few individuals unless trees within clusters are frequently quite closely related. The power of our battery of electrophoretic loci to discern genetically distinct individuals varied with genotype, with averages ranging from 94 to 99.9 per cent depending on relatedness.

Comparison of the observed distribution of genotypic differences between trees within clusters with the computer-generated expected distributions indicates that trees in these clusters most closely conform to the expected distribution of half-sibs (Fig. 1). The selfed and full-sib distributions differed significantly from the observed distribution $(P<0.01)$ using a KomolgorovSmirnov two-sample test. Neither the half-sib nor the unrelated distributions differed significantly from the observed distributions but the best fit (minimum D) was provided by the half-sib distribution. None of the trunks within clusters differed at more than six of the 10 loci examined.

Our estimate of average relatedness within clusters $(r=0.19)$ agrees with the results of the computergenerated distributions (Table 4). The estimate is slightly less than the expected value for half-sibs, but is significantly greater than zero. Individual estimates of relatedness vary widely among clusters.

Table 3 Probability of type II error (chance that two trees in a cluster will have identical 10-locus genotypes) assuming different degrees of relatedness. Cumulative error is the sum of error probabilities for all pairs of trunks that did not differ in genotype

\begin{tabular}{lllll}
\hline & \multicolumn{2}{l}{ Relationship } & \\
\cline { 2 - 4 } & Unrelated & Half-sib & Full-sib & \multirow{2}{*}{ Selfed } \\
\hline Mean & 0.001 & 0.004 & 0.013 & 0.060 \\
Minimum & $2 \times 10^{-8}$ & $4 \times 10^{-7}$ & $1 \times 10^{-5}$ & $4 \times 10^{-3}$ \\
Maximum & 0.009 & 0.018 & 0.064 & 0.275 \\
Cumulative & 0.330 & 0.965 & 3.202 & 14.769 \\
\hline
\end{tabular}

Table 2 Electrophoretic analysis of multi-trunk groups of Pinus flexilis at Pawnee Buttes

\begin{tabular}{lcccc}
\hline & \multicolumn{3}{c}{$\begin{array}{l}\text { Groups with multiple } \\
\text { genotypes }\end{array}$} \\
\cline { 3 - 4 } $\begin{array}{l}\text { Number of } \\
\text { trunks in } \\
\text { group }\end{array}$ & $\begin{array}{l}\text { Number of } \\
\text { groups }\end{array}$ & Number & $\begin{array}{l}\text { Percentage } \\
\text { of total }\end{array}$ & $\begin{array}{c}\text { Total number } \\
\text { of individuals }\end{array}$ \\
\hline 2 & 61 & 8 & 13.1 & 69 \\
3 & 29 & 8 & 27.6 & 40 \\
4 & 14 & 3 & 21.4 & 19 \\
5 & 3 & 0 & 0.0 & 3 \\
7 & 1 & 0 & 0.0 & 1 \\
Totals & 108 & 19 & 17.6 & 132 individuals \\
\hline
\end{tabular}




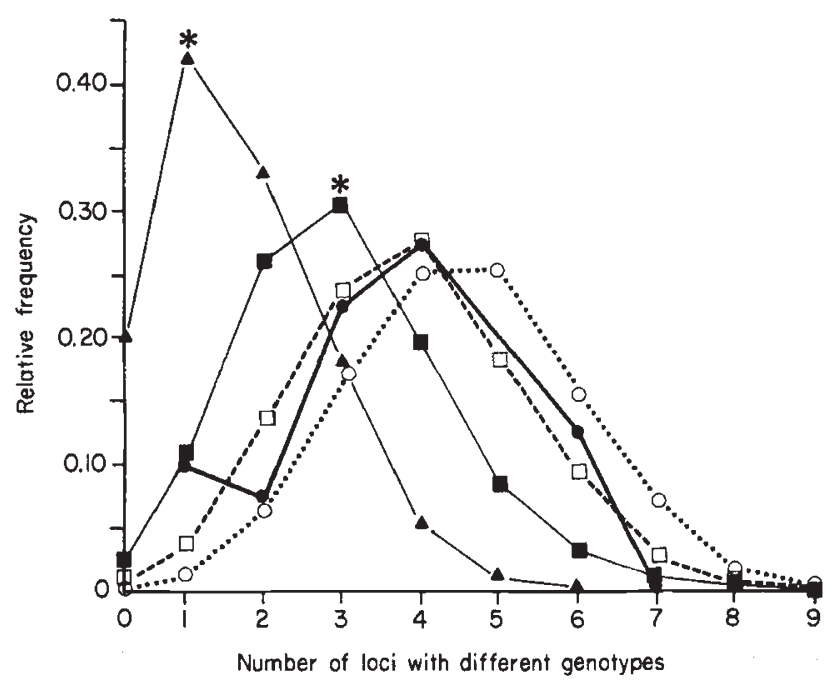

Fig. 1 Observed distribution of number of loci exhibiting different genotypes between pairs of trunks in multiple-trunk clusters and expected distributions based on different degrees of relatedness. (- - ) Observed, ( $\Delta$ ) selfs, ( $\square$ ) fullsibs, ( $\square$ ) half-sibs, (O) uncorrelated. *Differ from observed distribution $(P<0.01)$.

Table 4 Estimates of relatedness $(r \pm \mathrm{SE})$ within all limber pine clusters, between trees that have fused, and between trees in clusters with no obvious fusion. Relatedness values significantly greater than zero are indicated by asterisks

\begin{tabular}{llll}
\hline Category & $n$ & $r \pm \mathrm{SE} \dagger$ & Range $\neq$ \\
\hline All clusters & 19 & $0.19 \pm 0.104^{*}$ & $-0.86-0.88$ \\
$\quad$ Fused trees & 15 & $0.35 \pm 0.099^{* * *}$ & $-0.15-0.88$ \\
Separate trees & 15 & $0.05 \pm 0.114$ & $-0.86-0.58$ \\
\hline
\end{tabular}

${ }^{*} P<0.05,{ }^{* * *} P<0.001$.

$\dagger r$ for fused trees significantly different from separate trees $(P<0.05$, Mann-Whitney $U$-test $)$.

$\ddagger$ Negative values indicate cluster member gene frequencies differ more from each other than from population frequencies.

Examination of above-ground physical relationships among trees in clusters revealed that some cluster members had quite obviously fused together, while in other cases no fusion or grafting could be detected. Excavation and sectioning of one cluster of four seedlings revealed that wood tissue of two of the seedlings had clearly become grafted (Fig. 2). Xylem tissue of the seedlings was distinct for the first 8 years of growth but the last few years of xylem and the recent phloem tissue were continuous between the seedlings, presumably allowing translocation of water and nutrients. The other two seedlings in this cluster, while in close contact, exhibited no grafting. Our average relatedness

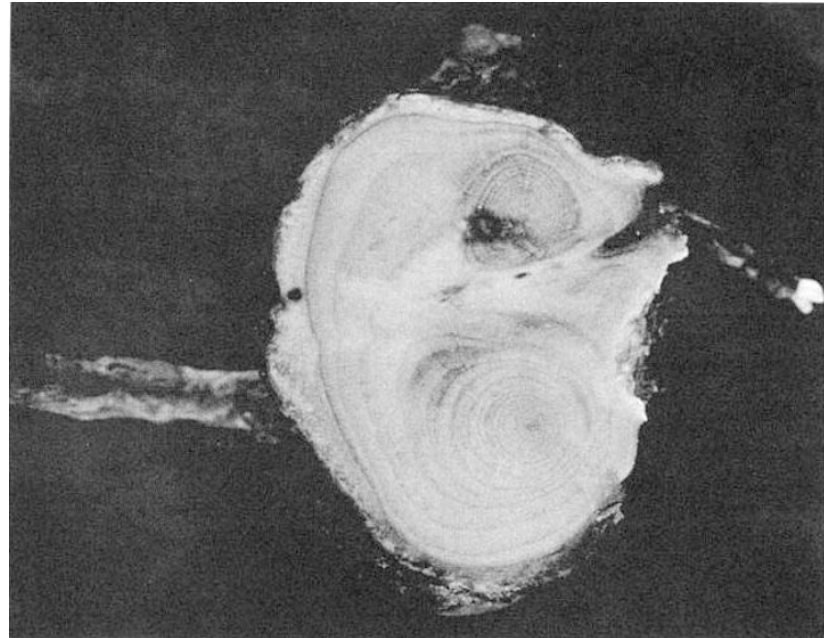

Fig. 2 Cross-section of the main stems of two members of a four-member tree cluster of Pinus flexilis showing xylem and phloem grafting. Section was made immediately below the ground surface.

estimates for all fused trees within clusters compared to those that were unfused (or where such fusion was not apparent), indicate that the trees that had fused were significantly more closely related $(P<0.05$, Table 4$)$.

\section{Discussion}

This is the third study in which it has been documented that multiple-trunk clusters of wingless-seeded pines contain multiple individuals. Despite the fact that we never observed corvids harvesting or caching in the area over a 3-year period, we suspect that these tree clusters grew from bird caches. While small mammals may also cache seeds, they are much more likely to act as seed predators by eating most of the seeds they harvest, and their caches are much less likely to be in suitable germination spots (Benkman et al., 1984). We also consider it unlikely that between 2 and 4 seeds frequently fall unassisted into the same safe site and germinate simultaneously. If this was the explanation, we would expect to see tree clusters in ponderosa pine and lodgepole pine forests, but the multi-trunk growth form is seldom seen in these species.

Despite the frequent presence of the multi-trunk growth form at Pawnee, fewer than 18 per cent of the putative clusters were found to contain two or more individuals. In some cases two or more individuals with the same 10-locus genotype may have grown together by chance but our calculations indicate that this could explain only a few of the 89 multiple-trunk entities which were electrophoretically identical. Thus, nearly 25 per cent of the Pawnee population consists of single trees with a multiple-trunk growth form. In 28 of these 
89 trees, the remainder of a central trunk that was cut or otherwise damaged provided evidence that lateral branches had grown into main trunks due to release from apical dominance. Factors such as cutting by humans, grazing, fire, unstable slopes and heat and aridity stress may have resulted in multi-trunk growth of individuals at Pawnee. However, in the majority of these trees evidence of such damage is absent. Soil accumulation around the tree bases may have obscured early damage in some cases. In some trees, upturned trunks served to identify side branches that had overcome leader dominance, as suggested by Lanner (1980). However, we also observed genetically distinct trees in clusters that were upturned at the base, and non-upturned trunks rising from a single root mass. As many tree clusters exhibited trunk fusion while other multi-trunk single trees had trunks that were not in contact at the ground surface, we conclude that spatial relations among trunks is a poor indicator of the number of trees present.

Our computer simulations and relatedness estimates indicate that trees in clusters are related, on average, as slightly less than half-sibs. The wide variation among individual cluster estimates may be partly due to sampling error and a limited amoung of genetic information (Quellar \& Goodknight, 1989). However, the estimator we used appears to be the best available (Pamillo, 1989), and the precision of our estimates is increased by the fact that our population allele frequencies are based on a survey of the entire population rather than a sample. Thus the wide range of individual estimates probably indicates that these clusters sometimes contain full-sibs as well as unrelated individuals.

Relatedness within seed caches is expected to vary depending on the timing of bird foraging, the extent of mixing within the sublingual pouch used to store and transport the seeds, and the number of seeds placed in a cache (Tomback, 1988). The results presented here suggest that complete mixing does not occur within the pouch because few clusters would be expected to contain sibling seeds under these circumstances. Relatedness might also vary from the seed cache to the seedling to the adult cluster stage as a result of differential mortality during this progression. However, our data from 19 clusters do not exhibit a significant correlation between $r$ and cluster age.

The fact that limber pine trees in nature are structured into kin groups indicates the potential for kin selection and/or competition. Kin selection theory predicts that genes for decreased intersib competition or altruism are favoured by natural selection if $r$ exceeds the ratio of fitness cost to benefit (Hamilton, 1964). While the average $r$ value within clusters at Pawnee is 0.19 , relatedness between pairs of individuals will either be $0,0.25$ or 0.5 , and can actually take on a wider range of values due to occasional selfing and inbreeding. Thus kin-selected traits, which operate only between the more closely related trees within clusters, could evolve more easily than generalized within-cluster traits, provided that trees possess some means of recognizing kin. Our data indicate that grafting occurs mainly between the more genetically similar trees within clusters, and thus limber pines appear to have some ability to detect relatedness of neighbours.

The ability to form grafts may or may not be a trait that has evolved through kin selection. Bormann (1966) called root grafting between white pines a 'noncompetitive' interaction, and documented the translocation of water and nutrients between grafted trees. $\mathrm{He}$ found that one of the major ecological features of grafting was the fact that weaker trees could benefit from grafts through translocation of nutrients, resulting in a much greater longevity. Thus related trees in a grafted pair could gain inclusive fitness from a graft if the weaker tree could survive to reproduce successfully when it would have otherwise died, and the ability to graft with kin would be favoured by selection.

Alternatively, Keeley (1988) has argued that translocation of nutrients between grafted trees is unlikely to be of adaptive significance and that grafting ability in trees has evolved primarily for the added support and stability of being anchored to other root systems. He cites several examples where root grafting appears to be more common in trees from swampy enrivonments in which increased support would be advantageous. Unfortunately, no assessment of relatedness was offered in these studies. At Pawnee, high winds and erosion rates, combined with shallow soils, may indeed place a premium on a larger support base, and these characteristics are typical of sites where limber pine is found. This explanation suggests that grafting would be advantageous to all individuals involved. However, root grafts may only be physiologically feasible where permitted by tissue compatibility between kin. In this event the trees involved could gain inclusive fitness from the added stability gained by their partners.

If grafting is adaptively advantageous, either as a result of increased stability or resqurce aquisition, inclusive fitness gains could promote the spread of grafting genes in populations where relatives come into contact. However, the relative costs and benefits of grafting are not fully understood. As Lohle \& Jones (1990) have suggested, graft formation could be a natural response when compatible tissues are forced into contact, with little or no adaptive significance.

Understanding the importance of these interactions can only come from a more detailed study of graft formation, inter-tree translocation and the fitness of rela- 
tives and non-relatives in tree clusters. Despite the possible benefits to trees being grouped in clusters, e.g. ready access to mates and a larger target for seed dispersers (Tomback \& Linhart, 1990), several lines of evidence indicate competition within clusters lowers fitness compared to solitary trees. Cone production is generally lower in cluster trees compared to solitary trees (R. Feldman \& D. F. Tomback, personal communication, W. Schuster, unpublished observations), and canopy development appears to be constrained in clusters (Tomback, 1988). At Pawnee there is a significant negative correlation between cluster age and tree number (Kendall's tau $=0.441, P<0.05$ ), which indicates that competition may lead to mortality through time. What we do not know is whether such competition is influenced by relatedness.

The data presented here indicates that limber pine is clustered in groups containing a variety of degrees of relatedness due to seed caching by birds, and that these trees are close enough to affect the fitness of their neighbours. Comparison to the data of Furnier et al. (1987) suggests a similar or higher degree of relatedness within whitebark pine clusters and due to the similarities among all bird-pine mutualisms, many of these bird-dispersed pines may frequently occur in clusters of relatives. Furthermore, in limber pine we have shown that interactions such as root and trunk fusion can differ with relatedness. In this system the prerequisites for kin selection are clearly fulfilled, and additional investigations could reveal whether interactions within these clusters have evolved in response to their effects on inclusive fitness.

\section{Acknowledgements}

Our interest in the possibility of kin selection in limber pine clusters was sparked by the papers of Diana Tomback and Yan Linhart. Valuable comments on this manuscript were provided by both of them as well as Michael Grant, Ric Charnov, Darren Sandquist and Ronald Lanner. We wish to thank James Hamrick for suggestions regarding electrophoresis with limber pine, Steve Levin and Eric Stark for field and laboratory assistance, and Grant Godbolt and the Pawnee National Grasslands for allowing us to work at the field site. This work was supported by NSF grant BSR8614937.

\section{References}

BALDA, R. F. 1980. Are seed caching systems coevolved? In: Proceedings of the XVII Congressus Internationalis Ornithologici, Berlin, pp. 1185-1191.

BENKMAN, C. W., BALDA, R. P. AND SMITH, C. C. 1984. Adaptations for seed dispersal and the compromises due to seed predation in limber pine. Ecology, 65, 632-642.

BORMANN, F. H. 1966. The structure, function, and ecological significance of root grafts in Pinus strobus L. Ecol. Monogr., 36, 1-36.

BRown, J. L. (1978) Avian communal breeding systems. Ann. Rev. Ecol. Syst., 9, 123-155.

CHARNOV, E. L. 1979. Simultaneous hermaphrodism and sexual selection. Proc. Natl. Acad. Sci. USA, 76, 2480-2484.

EllNER, S. 1986. Germination dimorphisms and parentoffspring conflict in seed germination. J. Theor. Biol., 123, $173-185$.

EPPERSON, B. K. 1990. Spatial patterns of genetic variation within plant populations. In: Brown, A. H. D., Clegg, M. T., Kahler, A. L. and Weir, B. S., (eds), Plant Population Genetics, Breeding, and Genetic Resources; Sinnaur Associates, Sunderland, MA, pp. 229-253.

FURNIER, G. R., KNOWLES, P., CLYDE, M. A. AND DANCIK, B. P. 1987. Effects of avian seed dispersal on the genetic structure of whitebark pine populations. Evolution, 41, 607-612.

HAIG, D. 1986. Conflict among megaspores. J. Theor. Biol., 123, 471-480.

HAIG, D. 1987. Kin conflict in seed plants. Trends Ecol. Evol., 2, 337-340.

HAMilton, w. D. 1963. The evolution of altruistic behavior. Am. Natur., 97, 354-356.

HAMilton, w. D. 1964. The genetical evolution of social behavior. I. and II. J. Theor. Biol., 7, 1-52.

KEELEY, J. E. 1988. Population variation in root grafting and a hypothesis. Oikos, 52, 364-366.

KING, J. N. AND DANCIK, B. P. 1983. Inheritance and linkage of isozymes in white spruce (Picea glauca). Can. J. Genet. Cytol., 25, 430-436.

KRESS, W. J. 1981. Sibling competition and the evolution of the pollen unit, ovule number and pollen vector in angiosperms. Syst. Bot., 6, 101-112.

LANNER, R. M. 1980. Avian seed dispersal as a factor in the ecology and evolution of limber and whitebark pines. In: Dancik, B. P. and Higginbotham, K. O. (eds), Proceedings of the Sixth North American Forest Biology Workshop, Edmonton, Alberta, pp. 15-48.

LANNER, R. M. AND VANDER WALL, S. B. 1980. Dispersal of limber pine seed by Clark's Nutcracker. J. Forest, 78, 637-639.

LEVIN, D. A. AND KERSTER, H. W. 1974. Gene flow in seed plants. Evolut. Biol., 7, 139-220.

LINHART, Y. B., MITTON, J. B., STURGEON, K. B. AND DAVIS, M. L. 1981. Genetic variation in space and time in a population of ponderosa pine. Heredity, 46, 407-426.

LINHART, Y. B. AND TOMBACK, D. F. 1985 . Seed dispersal by nutcrackers causes multi-trunk growth form in pines. Oecologia, 67, 107-110.

LITTLE, E. L., JR. 1971. Atlas of the United States Trees, Vol. 1. Conifers and Important Hardwoods. USDA, Forestry Service Miscellaneous, Washington, DC, Publication 1146.

LOEHLE, C. AND JONES, R. H. 1990. Adaptive significance of root grafting in trees. Funct. Ecol., 4, 268-271.

LOVELESS, M. D. AND HAMRiCK, J. L. 1984. Ecological determi- 
nants of genetic structure in plant populations. Ann. Rev. Ecol. Syst., 15, 65-95.

MEAGHER, T. R. AND THOMPSON, E. 1986. The relationship between single parent and parent pair genetic likelihoods in genealogy reconstruction. Theor. Pop. Biol., 29, 87-106.

MITTON, J. B., LINHART, Y. B., STURGEON, K. B. AND HAMRICK, J. L. 1979. Allozyme polymorphisms detected in mature needle tissue of ponderosa pine. J. Heredity, 70, 86-89.

PAMILo, P. 1989. Estimating relatedness in social groups. Trends Ecol. Evol., 4, 353-355.

POULIK, M. D. 1957. Starch gel electrophoresis in a discontinuous system of buffers. Nature, 180, 1477-1479.

QuellaR, D. C. 1983. Kin selection and conflict in seed maturation. J. Theor. Biol., 100, 153-172.

QUELLAR, D. C. 1989. Inclusive fitness in a nutshell. Oxford Surveys in Evol. Biol., 6, 73-109.

QUELLAR, D. C. AND GOODKNIGHT, K. F. 1989. Estimating relatedness using genetic markers. Evolution, 43, 258-275.

RITLAND, K. 1990. Gene identity and the genetic demography of plant populations. In: Brown, A. H. D., Clegg, M. T., Kahler, A. L. and Weir, B. S. (eds), Plant Population, Genetics, Breeding, and Genetic Resources, Sinnauer Associates, Sunderland, MA, pp. 181-199.

ROELOFFS, R. AND RIECHERT, S. E. 1988. Dispersal and population-genetic structure of the cooperative spider, Agelena consociata in west African rainforest. Evolution, 42, 173-183.

SCHAAL, B. A. 1975. Population structure and local differentiation in Liatris cylindracea. Am. Natur., 109, 511-528.

SEGER, J. 1990. Cooperation and conflict in insects. In: Krebs, J. R. and Davies, N. B. (eds), Behavioural Ecology: An Evolutionary Approach, 3rd edn, Blackwell Scientific Publications Ltd, Oxford, pp. 338-373.
SELANDER, R. K., SMITH, M. H., YANG, S. Y. AND GENTRY, J. B. 1971. Biochemical systematics in the genus Peromyscus. I. Variation in the old-field mouse. Stud. Genet. VI. Univ. Texas Publ., 7103, 49-90.

SOKAL, R. R. AND ROHLF, F. J. 1981. Biometry, 2nd edn. W. H. Freeman and Co., New York.

TOMBACK, D. F. 1982. Dispersal of whitebark pine seeds by Clark's Nutcracker: a mutualism hypothesis. J. Anim. Ecol., 51, 451-467.

TOMBACK, D. F. 1988. Nutcracker-pine mutualisms: multitrunk trees and seed size. In: Ouellet, H. (ed.), Acta XIX Congressus Internationalis Ornithologici, Vol. 1, University of Ottawa Press, Ottawa, Canada, pp. 518-527.

TOMBACK, D. F. AND KRAMER, K. A. 1980. Limber pine seed harvest by Clark's Nutcracker in the Sierra Nevada: timing and foraging behavior. Condor, 82, 467-468.

TOMBACK, D. F. AND LINHART, Y. B. 1990. The evolution of birddispersed pines. Evol. Ecol., 4, 185-219.

TOMBACK, D. F, HOFFMAN, L. A. AND SUND, S. K. 1990. Coevolution of whitebark pine and nutcrackers: implications for forest regeneration. In: Proceedings Whitebark Pine Ecosystems: Ecology and Management, of a High Mountain Resource. USDA Forestry Service Intermountain Forest and Range Exper Station, Ogden, UT (in press).

Trivers, R. L. 1974. Parent-offspring conflict. Am. Zool., 14, 249-264.

WESTOBY, M. 1981. How diversified seed germination behavior is selected. Am. Natur., 18, 882-885.

WESTOBY, M. AND RICE, B. 1982. Evolution of seed plants and inclusive fitness of plant tissues. Evolution, 36, 713-724.

woodmansee, R. G. 1977. Clusters of limber pine trees: a hypothesis of plant-animal coaction. Southwest Natur., 21, 511-517. 